\title{
Geociências
}

\section{Informações geoambientais derivadas de imagens de radar (R99B/SIPAM) e ópticas (LANDSAT/TM5) em jazimento de minério de ferro em Carajás}

\section{(Environmental informations derived from radar (R99B/SIPAM) and optical (LANDSAT/TM5) images on iron ore deposit in Carajás)}

Maria Carolina de Morais Aluna de doutorado do curso de Geologia Ambiental e Conservação de Recursos Naturais do Departamento de Geologia (DEGEO/UFOP).E-mail:mcarolina@degeo.ufop.br

Paulo Martins Pereira Junior

Professor do Curso de Engenharia Geológica e Engenharia Ambiental da Pós-Graduação em Geologia Ambiental e Conservação de Recursos Naturais do Departamento de Geologia (DEGEO/UFOP). Pesquisador do CETEC - Belo Horizonte.E-mail: paulo.martins@cetec.br

Pesquisador Titular III da Divisão de Sensoriamento Remoto (DSR), vinculada à Observação da Terra (OBT) do INPE - São José dos Campos. E-mail: waldir@ltid.inpe.br

\section{Resumo}

Um dos impactos ambientais mais significativos em minerações de ferro está associado com as modificações da paisagem, especialmente em regiões de floresta equatorial, como no depósito N1, localizado na Província Mineral de Carajás. O uso da tecnologia do sensoriamento remoto tem mostrado muita eficiência e baixo custo no levantamento de informações ambientais nessa região. Imagens ópticas e de radar permitem a extração de informações complementares sobre a cobertura superficial e as alterações antrópicas, sob uma visão sinóptica do tratamento desses impactos. O principal objetivo dessa pesquisa é a obtenção de um conjunto de informações ambientais para futura implementação em um sistema de conhecimento que possa ser utilizado em regiões com contextos geoambientais similares.

Palavras-chave: Minerações de ferro, impactos ambientais, sensoriamento remoto, informações ambientais.

\begin{abstract}
One of the most significant environmental impacts of iron-ore mining is associated with landscape modifications, particularly in equatorial forest conditions around the N1-deposit located in the Carajás Mineral Province. The use of remote sensing data can be an excellent alternative to decrease costs for environmental data acquisition in this region. Integrated optical and radar images were used to extract complementary information about the landscape's natural conditions and anthropogenic changes in a prospective vision of future use impacts. The main objective of this research is to obtain a set of environmental data for future implementation of a knowledge-system which can be of common use to other areas or regions with similar characteristics.
\end{abstract}

Keywords: Iron-ore mining, environmental impacts, remote sensing, environmental data. 
Informações geoambientais derivadas de imagens de radar (R99B/SIPAM) e ópticas (LANDSAT/TM5)...

\section{Introdução}

A implantação e a operação de uma mineração de ferro a céu aberto acarretam modificações no meio ambiente, afetando, substancialmente, as estruturas relacionadas ao meio físico e biótico. Os impactos ambientais mais proeminentes, mas não únicos, em função dos vários tipos de áreas de influência de uma mineração (Martins Jr. \& Carneiro, 2006), estão relacionados às configurações da cava, da barragem de rejeito e da pilha de estéril (Ripley et al., 1996). Na serra dos Carajás, o tratamento das questões ambientais relacionadas à mineração deve ser mais rigoroso, em face da fragilidade do ambiente amazônico.

No que diz respeito às atividades de mineração da serra dos Carajás, o licenciamento ambiental dá-se em uma instância federal, por meio de um DecretoLei $\mathrm{N}^{\circ} 2.486$, de 2 de fevereiro de 1998, que cria a Floresta Nacional de Carajás. Como a área em questão encontra-se em vias de ser lavrada a céu aberto, informações ambientais devem ser obtidas para contribuir com o cumprimento da legislação ambiental, no sentido de indicar as áreas de influência do empreendimento (Martins Jr. \& Carneiro, 2006), as melhores locações para barragem de rejeito e pilha de estéril e as áreas que devem ser preservadas, como, por exemplo, os campos rupestres inseridos no bioma da floresta.

Tais informações são relevantes para a definição de critérios geoambientais, em escala de 1:100.000, visando à implementação de um Sistema de Arquitetura de Conhecimentos (Martins Jr., 2008) a ser implementado para um jazimento de ferro (N1). Para tanto, utilizamse das várias técnicas do sensoriamento remoto ativo e passivo, cujas potencialidades ainda não foram plenamente avaliadas como ferramentas para gestão de lavra a céu aberto em sistemas florestais úmidos.

\section{2. Área de estudo}

A área de estudo compreende o depósito de ferro N1, localizado na Província Mineral de Carajás. Inserido na reserva denominada Floresta Nacional dos Carajás (Flona Carajás), N1 está sobre um platô situado a sudeste no Estado do Pará, na borda norte da serra dos Carajás, perfazendo uma área de aproximadamente $24 \mathrm{~km}^{2}$ (Figura 1). A região de Carajás destaca-se por abrigar as maiores jazidas de ferro do mundo com diversas minas em produção.

\subsection{Litoestratigrafia, geomorfologia e vegetação}

Os depósitos de ferro da serra dos Carajás estão inseridos na seqüência metavulcanossedimentar do Grupo Grão-Pará (Tolbert et al., 1971; Beisegel et al., 1973), com idade de $2593 \pm 260 \mathrm{Ma}$, obtidas por dados Sm-Nd em jaspilitos (Lobato et al., 2005). O Grupo Grão-Pará é composto por três unidades principais:

a) Unidade vulcânica máfica Inferior denominada de Formação Parauapebas em Meireles et al. (1984), é representada por rochas máficas verdes hidrotermalmente alteradas (greenstones), basaltos, traquiande-

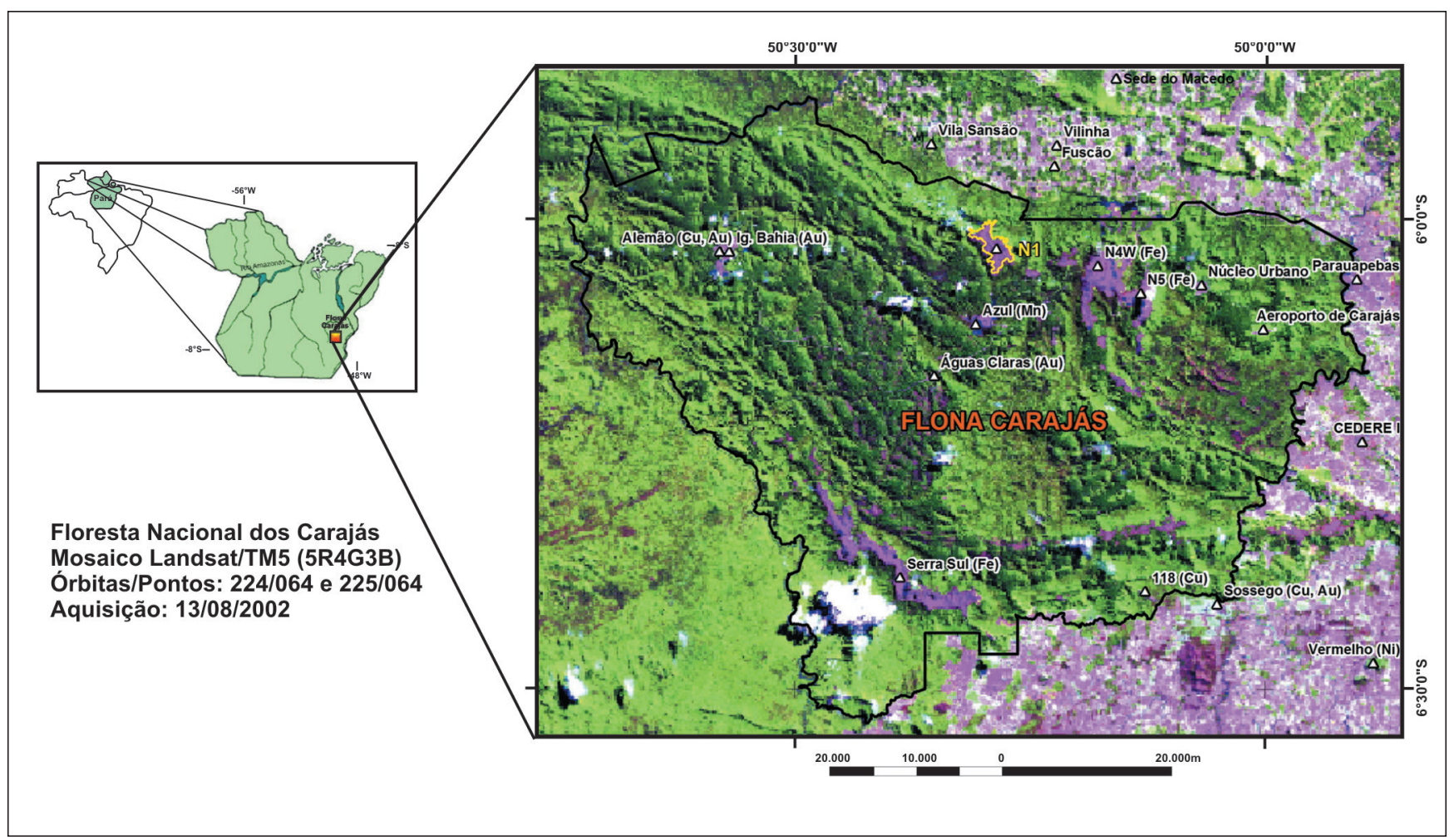

Figura 1 - Flona Carajás e N1: as cores magentas que circundam a flona correspondem às áreas desmatadas. 
sitos e, em menor quantidade, riolitos e contribuições piroclásticas de natureza básica a intermediária.

b) Unidade de jaspilitos intermediária denominada Formação Carajás (Tolbert et al. 1971), é constituída, principalmente, por formação ferrífera bandada, com alternância de bandas de chert e de óxidos de ferro, com hematita e magnetita subordinada.

c) Unidade vulcânica máfica superior é representada por derrames porfiríticos e amigdaloidais de basaltos e andesitos basálticos, semelhantes aos da unidade máfica inferior, intercalados com horizontes piroclásticos.

Em relação à geomorfologia, o depósito de N1 encontra-se inserido no domínio centro-norte do Planalto Dissecado do sul do Pará, sendo caracterizado por maciços residuais de topo aplainado e conjuntos de cristas e picos interpenetrados por faixas de terrenos rebaixados (Boaventura, 1974). Nesse domínio, o relevo montanhoso apresenta altitudes máximas de $900 \mathrm{~m}$ e de $135 \mathrm{~m}$ nos terrenos rebaixados (Figura 2). Sobre as porções mais altas dessas montanhas, ocorrem as coberturas lateríticas do depósito N1, dispostas sobre o platô com uma variação altimétrica local em torno de 200m, mapeadas por Resende e Barbosa (1972).

A vegetação que cresce sobre a canga na área de N1 é descrita como campo rupestre por Silva et al. (1992) e é, predominantemente, arbustiva, com poucos indivíduos de porte arbóreo, destacando-se como clareira em relação à floresta tropical pluvial que a circunda. As espécies desenvolvidas nas partes mais elevadas do platô são gramíneas, que ocorrem devido à presença de muitos afloramentos e ao pequeno acúmulo de matéria orgânica nas fendas das cangas. Por outro lado, nas encostas dessas elevações, ocorrem deposição de solo e acúmulo de matéria orgânica, permitindo o desenvolvimento de espécies de porte reduzido. Na base dos morros, a vegetação é mais abundante, com ocorrência de espécies arbóreas mais desenvolvidas.

\section{Material e métodos}

Imagens ópticas (LANDSAT/TM5) e de radar foram utilizadas nessa investigação. As imagens de radar provêm do sensor aerotransportado SAR-R99B do SIPAM (Sistema de Proteção da Amazônia). A resolução espacial original foi degradada de 3 para $11 \mathrm{~m}$ e as faixas de vôo obtidas sobre Carajás foram mosaicadas, processamentos estes realizados no CENSIPAM (Centro Gestor e Operacional do Sistema de Proteção da Amazônia). O objetivo dessa missão foi simular um radar orbital, o MAPSAR (Multi-Application Purpose SAR), em fase de concepção entre Brasil e Alemanha, e avaliar a sua viabilidade em aplicações geológicas na Amazônia. Os sobrevôos realizados em Carajás em banda L foram uma iniciativa conjunta do INPE, IG/UNICAMP e FEMA (MT) e com o apoio da VALE. Mais detalhes sobre a missão e suas aplicações podem ser encontrados em Paradella et al. (2006), Mura et al. (2007) e outros.

Dados de relevo obtidos do Modelo Digital de Elevação (MDE) do levan- tamento SRTM/NASA foram utilizados para a ortorretificação da imagem óptica. Em um estudo relativo à precisão altimétrica do MDE/SRTM, para a Amazônia, Santos et al. (2005) indicam a utilização daquele modelo para escala de 1:100.000, em detrimento de modelos gerados a partir de cartas topográficas. Para o relevo montanhoso de Carajás, Oliveira (2008) também encontrou resultados satisfatórios sobre a precisão altimétrica do MDE/SRTM, com padrão classe A para escala 1:100.000. Desta forma, a utilização do MDE/SRTM, nessa pesquisa, é pertinente para a escala de trabalho utilizada. As informações referentes aos dados de sensoriamento remoto encontram-se sintetizadas na Tabela 1 .

O processamento digital efetuado nas imagens de radar e ópticas encontra-se sintetizado no fluxograma da Figura 3. Na imagem LANDSAT/TM5 foram realizadas a ortorretificação, a Análise por Componentes Principais (ACP) e a integração via IHS/RGB (Mather, 1987). Esta última etapa foi realizada com a utilização as imagens de radar do mosaico do SAR-R99B (hh, hv e vv), processa-

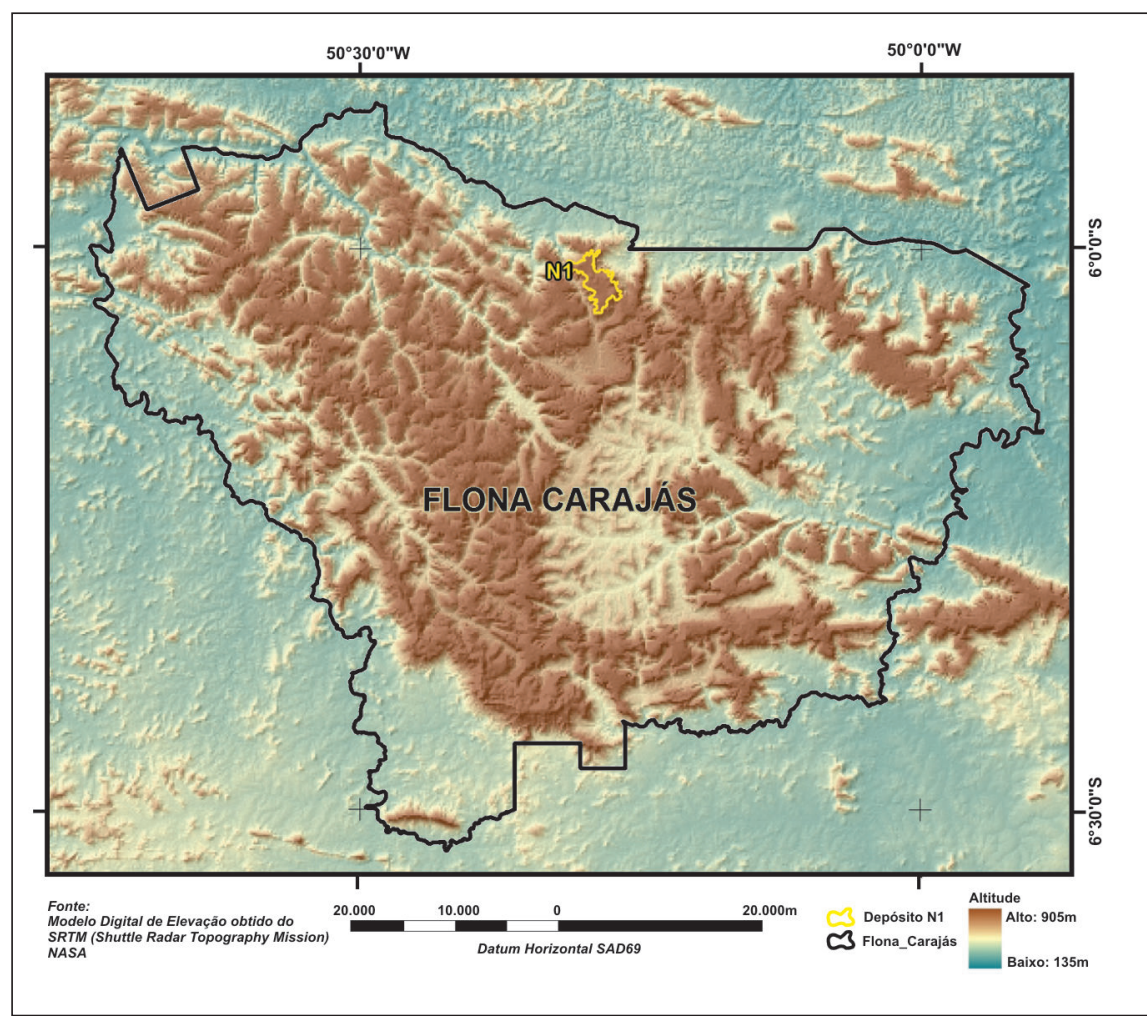

Figura 2 - Modelo Digital de Elevação da região de Carajás, com destaque para N1. 
das com a correção radiométrica e a reamostragem de pixel. Todos os processamentos realizados nas imagens ópticas e de radar foram conduzidos através do software Geomatica PCI, versão 9.0 (PCI, 2003).

Em reação ao Modelo de Elevação do Terreno (MDE) obtido do levantamento SRTM/NASA, as inconsistências apresentadas, tais como valores negativos e ausência de informação, foram corrigidas e substituídas por valores consistentes interpolados com base na média de valores de níveis de cinza adjacentes. Posteriormente, uma reamostragem do tamanho do pixel foi realizada, interpolando os referidos valores por variáveis regionalizadas de 90 para $30 \mathrm{~m}$. O MDE final foi utilizado, juntamente com pontos de controle de campo, na ortorretificação da imagem LANDSAT/TM5.

$\mathrm{Na}$ Análise por Componentes Principais (ACP), utilizaram-se as bandas 1,2,3,4,5 e 7 do LANDSAT/TM, de forma a se obterem dois conjuntos; o conjunto das bandas 1,2 e 3 e o conjunto das bandas 5 e 7 , eliminando, assim, toda informação redundante nessas faixas. As bandas TM 1, 2 e 3 tendem a exibir elevada correlação, em função dos processos de absorção de energia em pigmentos; as bandas 5 e 7 tendem a apresentar uma maior redundância de informação, pois são controladas, espectralmente, por absorções vinculadas ao teor de água do tecido foliar. Finalmente, a banda 4 foi utilizada separadamente, por ser útil na determinação do conteúdo da biomassa e no delineamento de corpos d'água.

A integração de dados de sensoriamento remoto distintos via IHS-RGB tem sido amplamente utilizada para mapeamentos geológicos. Trabalhos de integração de imagens de radar com imagens ópticas e dados auxiliares (geológicos, geofísicos, geoquímicos, etc.) são pioneiros na Província Mineral de Carajás, destacando-se, entre outros, Paradella et al. (2000) e Paradella et al. (2001).

$\mathrm{Na}$ integração das imagens de radar com as imagens ópticas, foram usados, como canais de entrada (RGB/IHS): a banda 4 (1), a componente principal 1

\begin{tabular}{c|c|c|c}
\hline Tabela 1 - Dados utilizados. & \multicolumn{4}{|c}{} \\
\hline Dado & $\begin{array}{c}\text { Resolução } \\
\text { espacial (m) }\end{array}$ & Aquisição & Bandas \\
\hline Landsat/TM5 & $30 \times 30$ & Ago - 02 & $1,2,3,4,5, \mathrm{e} 7$ \\
\hline SAR-R99B & $11 \times 11$ & Jun - 05 & L (hh, hv, vv) \\
\hline MDE - SRTM/NASA & $90 \times 90$ & Fev - 02 & 1 \\
\hline
\end{tabular}

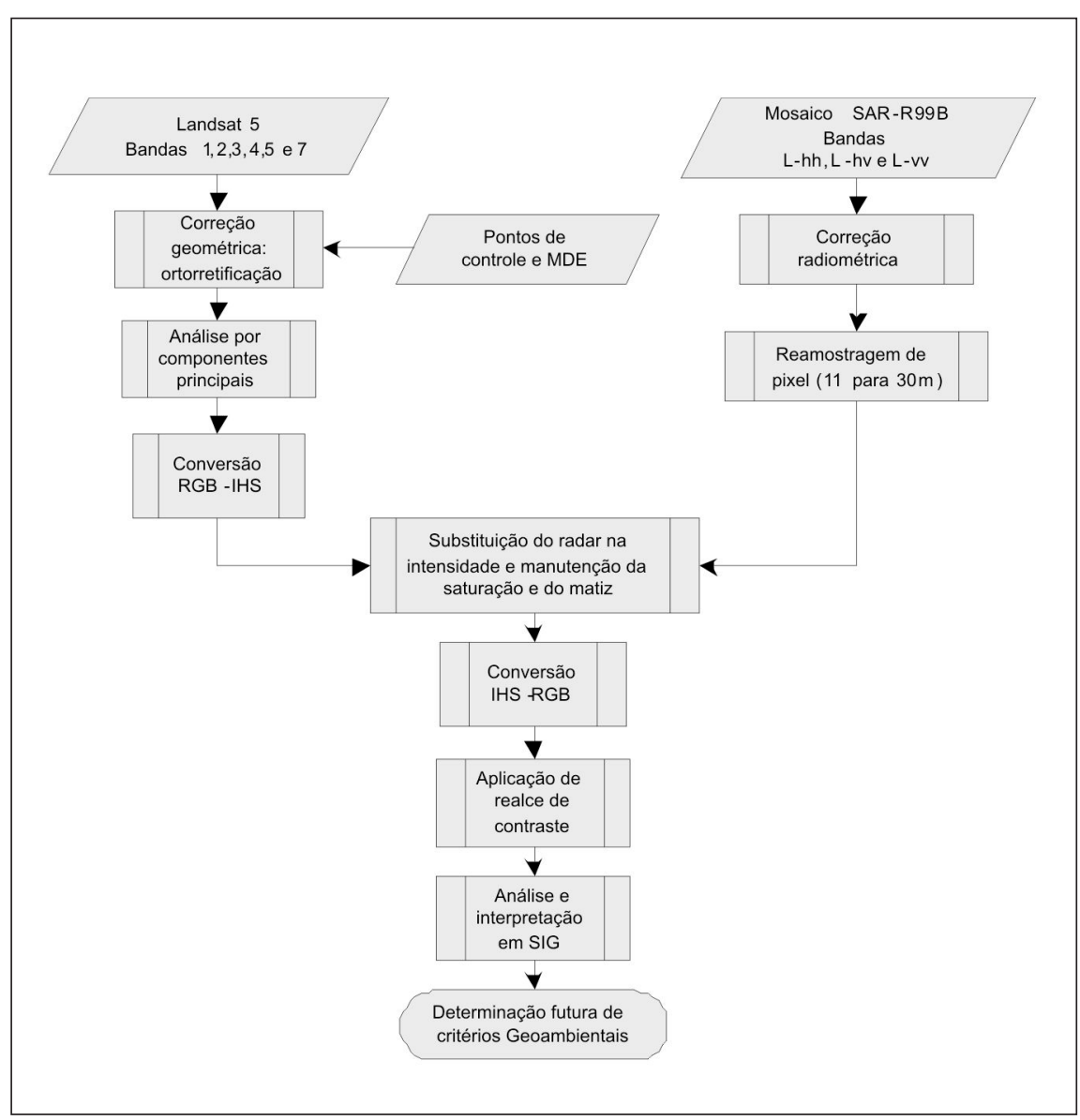

Figura 3 - Etapas da metodologia.

(CP-1) das bandas TM 5, 7 (2) e a (CP-1) das bandas TM 1,2 e 3 (3). Na transformação reversa (IHS-RGB), houve a substituição das imagens de radar na intensidade, com a manutenção dos canais de matiz e a saturação por meio de um modelo hexacone. Esse modelo é uma representação das cores por meio de coordenadas cilíndricas de um hexacone. Os matizes são representados por uma posição angular ao longo do topo do hexacone. A saturação é dada pela distância do eixo vertical à superfície lateral do hexacone e a intensidade é representada pela distância vertical da base ao topo do hexacone (Mather, 1987).

As imagens de radar SAR-R99B (L-hh, L-hv e L-vv) substituídas na intensidade foram, previamente, submetidas à correção radiométrica, com filtragem para atenuação do speckle. $\mathrm{O}$ filtro Enhanced Frost, janela $3 \times 3$, foi aplicado às três cenas, com as polarizações hh, hv e vv. Em seguida, essas imagens tiveram o pixel reamostrado de 11 para $30 \mathrm{~m}$, para serem integradas com as imagens ópticas. Essa degradação, na resolução espacial dos dados de radar, deve- 
se ao compromisso entre a escala de trabalho ideal para a finalidade desejada e a possibilidade de ortorretificação apenas da imagem óptica.

Os resultados das integrações das imagens ópticas com as imagens de radar foram três produtos integrados, correspondentes às polarizações hh, hv e vv. Esses produtos foram submetidos a um contraste linear e posteriormente analisados e interpretados em um Sistema de Informações Georreferenciadas (SIG), para posterior aplicação em estudos sobre critérios para gestão geoambiental do depósito de N1 e entorno. Para tanto, buscou-se adaptar a metodologia aplicada na bacia do Rio Paracatu por Martins Jr. et al. (2006), para a área em ques- tão, de forma a compor um sistema de conhecimento para o depósito em vias de ser lavrado, que possa ser aplicado em áreas com contexto geoambiental semelhante. Dessa forma, foram analisados as áreas de vegetação de floresta e campos rupestres, as áreas desmatadas, as áreas de mineração e a relação de todas essas variáveis com os aspectos fisiográficos que os produtos de sensoriamento remoto permitiram vislumbrar.

\section{Resultados}

Em relação aos produtos obtidos da integração via APC e IHS/RGB das imagens ópticas LANDSAT/TM5 com o SAR R99B/SIPAM, resultados distintos foram obtidos em função das diferentes polarizações do levantamento com o radar. A integração que mostrou maior capacidade de diferenciação de alvos refere-se ao produto integrado óptico com a imagem de radar hh (Figura 4).

$\mathrm{Na}$ Figura 4, nota-se uma intensa fragmentação da paisagem, com as variações de matizes representando as diferenças espectrais da cobertura vegetal da floresta, dos campos rupestres, das atividades antrópicas e das atividades de mineração.

A variação de matizes, na cobertura florestal,propicia melhor discriminação da floresta, juntamente com a variação do relevo, realçado pelo radar. As áreas

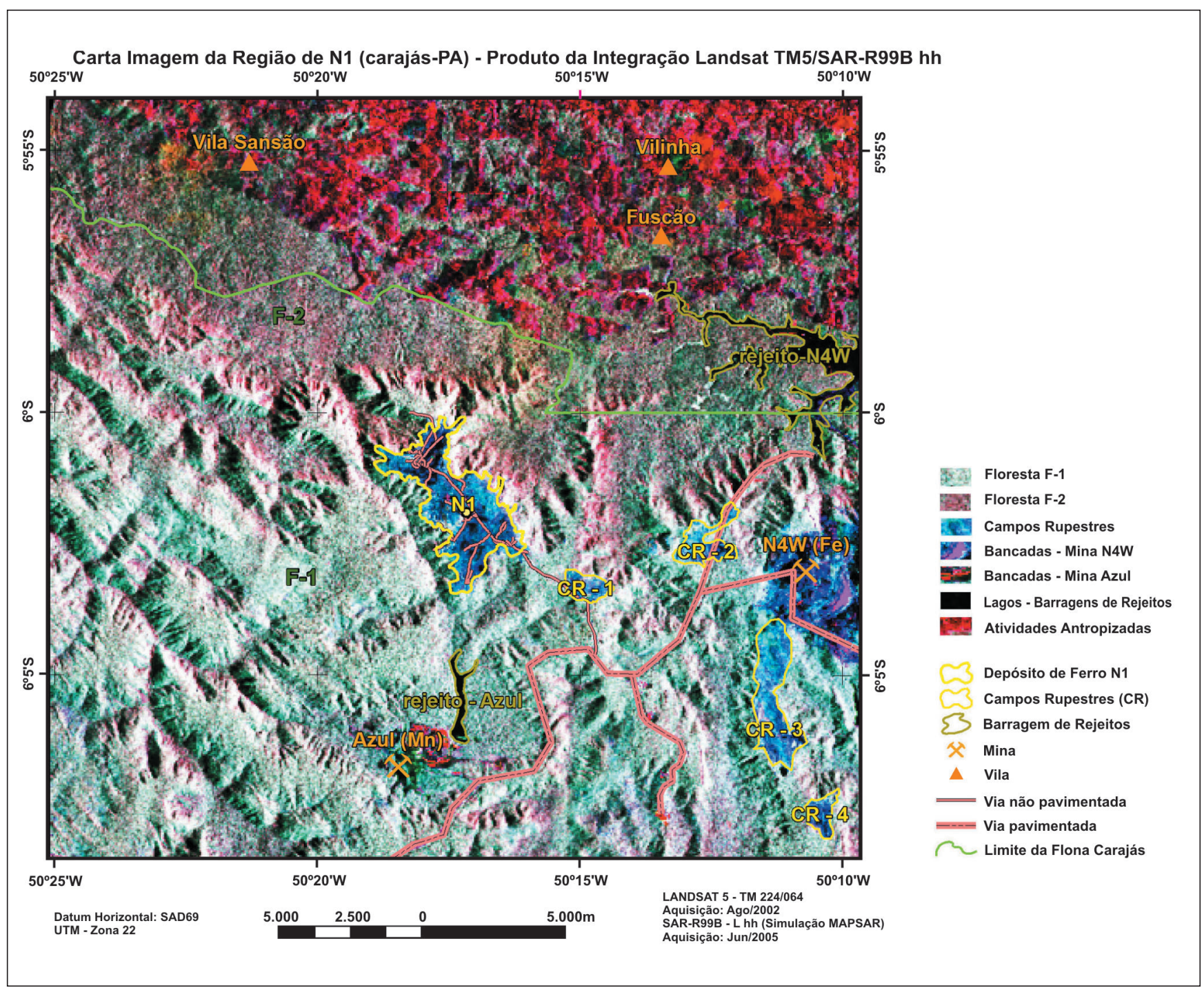

Figura 4 - Carta-imagem semi-regional da integração LANDSAT/TM5-ACP/SAR-R99B. 
de floresta mais altas (F-1) apresentam matizes esverdeados e as mais baixas (F-2), matizes verde-avermelhados.

As variações de campos rupestres no platô de N1 também são distinguidas com matizes azuis mais claros, que representam a vegetação rasteira presente nas partes mais elevadas em N1 (Figura 5). Outras áreas de vegetação de campos rupestres são indicadas para preservação (CR-1, CR-2, CR-3 e CR-4), que, juntas, perfazem, aproximadamente, 10 $\mathrm{Km}^{2}$. Na área da mina de $\mathrm{N} 4 \mathrm{~W}$, nota-se uma variação rósea, que está relacionada às bancadas da cava, o que permite um controle sobre o avanço das mesmas, na escala de trabalho utilizada.

As áreas com coloração avermelhada, localizadas a norte de N1, apresentam-se intensamente desmatadas e encontram-se fora dos limites norte da Flona Carajás. Elas ilustram, claramente, o impacto das atividades antropogênicas não relacionadas às atividades de mineração, muito freqüentes na Amazônia.

Duas barragens de rejeito são diferenciadas na área, uma parcialmente relacionada à mina de ferro N4W e outra relacionada à mina de manganês (áreas avermelhadas e esverdeadas). Na primeira, é possível distinguir vegetação aquática preservada nos braços das drenagens graças à resposta do radar na polarização hh.

\section{Conclusões}

As informações ambientais obtidas com o uso da tecnologia dos produtos integrados de imagens de radar e ópticas permitem, inicialmente, visualizar as diferenças dos matizes e do relevo entre os diversos alvos que compõem a paisagem de N1 e do entorno na área analisada. Áreas de florestas preservadas são abundantes nos limites da flona, mas mostram-se pressionadas pelo avanço das atividades antrópicas, evidenciando a necessidade de estudos mais elaborados sobre a temática - áreas de influência. Em relação à vegetação de campos rupestres, foi possível indicar áreas para preservação desse importante ecossistema, inserido na área da flona. No depósito N1, foi possível, ainda, discriminar matizes distintos, relacionados às variações de vegetação no platô, que, por sua vez, apresentam nítido controle geobotânico. Com base nessas diferen- tes respostas da cobertura superficial na paisagem do entorno de N1, a tecnologia da integração de radar com imagens ópticas pode ser utilizada para levantamento prévio de informações ambientais em escala semi-regional a local. Estudos em escala de detalhe no depósito de N1 vêm sendo conduzidos de forma a constituir parte de um Sistema de Arquitetura de Conhecimentos, que forneça critérios para acompanhamento, monitoramento e medições passíveis de serem implementados em um jazimento de ferro a ser lavrado a céu aberto. Também esses estudos serviriam de modelo aplicável a outras áreas com semelhante contexto geoambiental.

\section{Agradecimentos}

Os autores agradecem ao Instituto Nacional de Pesquisas Espaciais (INPE), pelas imagens de radar e apoio em trabalhos de campo; à VALE, na pessoa do geólogo Lambertus C. Schardt, pela infra-estrutura de campo; à Viviane Lasmar Pacheco Monte e a Fabiano Gumier Costa do Instituto Brasileiro do Meio Ambiente e dos Recursos Naturais Renováveis (IBAMA - Flona Carajás), pelo apoio durante a realização do campo.

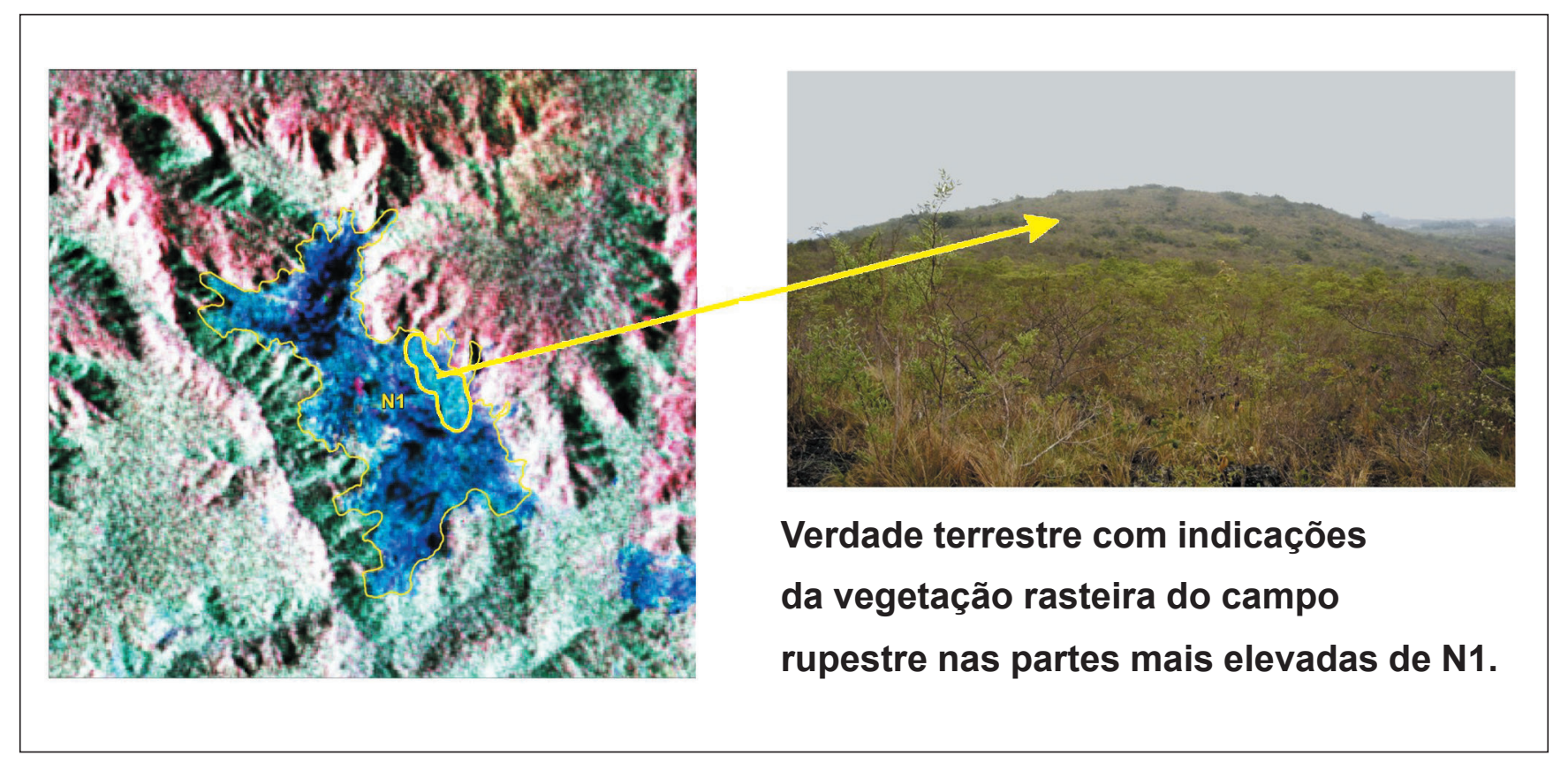

Figura 5 - Detalhe da imagem integrada óptica/radar e verdade terrestre de campo rupestre em N1, evidenciando a correlação. 
Maria Carolina de Morais et al.

7. Referências

\section{bibliográficas}

BOAVENTURA, R. Geomorfologia da Folha SB.22 - Araguaia e parte da Folha SC.22 - Tocantins. Rio de Janeiro: MME, DNPM, 1974. (Projeto RADAMBRASIL, v.4).

LOBATO, L.M., ROSIÈRE, C.A., SILVA, R.C.F., ZUCCHETTI,M., BAARS, F.J., SEOANE, J.C.S., RIOS, F.X., PIMENTEL, M., MENDES, G.E, MONTEIRO, A.M. A mineralização hidrotermal de ferro da Província Mineral de Carajás - Controle estrutural e contexto na evolução metalogenética da província. In: ADIMB/DNPM. Caracterização de depósitos minerais em distritos mineiros da Amazônia. Brasília: DNPM-CT/ MINERAL-ADIMB, 2005. cap. 2, p.2192. 782p.

MARTINS Jr., P.P., CARNEIRO, J.A. Guia prático de requisição de perícias ambientais. Belo Horizonte: Ministério Público de MG. 2006. p. 34-47. 96p.

MARTINS Jr., P.P., MARQUES, A.F.S.M., VASCONCELOS, V.V., ENDO, I., NOVAES, L.A.A., PEREIRA, M.A.S. Modelo de integração de conhecimentos interdisciplinares para auxílio à decisão - os plantios ecológico-econômicos em zonas de recarga de aqüíferos. Belo Horizonte: CETEC, 2006. p.24-48 (Nota Técnica-Tomo 3).

MARTINS JR., P.P., PAIVA, D.A., PEREIRA, J.S., ABREU Jr., J.C., DINIZ, C.P.L. 2008. Projeto ACEE. Arquitetura de conhecimentos em ecologiaeconomia para gestão ambiental de bacia hidrográfica. Belo Horizonte: CNPq Edital 14-2004 Inovação Tecnológica em Ciência da Computação/ CETEC/UFOP. Projeto em desenvolvimento. CNPq (2008).
MATHER, P.M. Computer processing of remotely-sensed images: an introduction. Chichester: John Wiley, 1987. 325 p.

MEIRELES et al. Geologia das folhas Carajás e Rio Verde, Província Mineral dos Carajás, Estado do Pará. In: CONGRESSO BRASILEIRO DE GEOLOGIA, 33. Rio de Janeiro, 1984. Anais... Rio de Janeiro: Sociedade Brasileira de Geologia, 1984. v.5, p.2164-2174.

MURA, J. C., PARADELLA, W. R., DUTRA, L. V. MAPSAR image simulation based on L-Band polarimetric SAR data of the airborne SAR R99 sensor of the CENSIPAM. In: SIMP. BRAS. SENS. REM, 13, 2007. Florianópolis. Anais... Florianópolis: INPE/ SELPER, 2007. CD ROM, p. 4841-4848.

OLIVEIRA, C.G., PARADELLA, W.R. An assessment of the altimetric information derived from spaceborne SAR (RADARSAT-1, SRTM3) and optical (ASTER) data for cartographic application in the Amazon Region. Sensors, v.8, p. 3819-3829, 2008.

PARADELLA, W. R., SANTOS, A. R.; VENEZIANI, P., SILVA, M. M. Q., MURA, J. C., RABELO, T. N.; KNUST. S. S. A., TERUIYA, R.K., MIRANDA, F. P., SOUZA FILHO, C. R., CRÓSTA, A. P. O satélite MAPSAR do Programa Espacial Brasileiro: concepção, estado atual e potencial para aplicações nas Geociências. In: CONGRESSO BRASILEIRO DE GEOLOGIA, 43, 2006. Aracaju. Anais... Aracaju: SBG, 2006. v. 1, p. 152.

PARADELLA, W. R., SANTOS, A. R., VENEZIANI, P., MORAIS, M. C. de. O sinergismo de imagens Standard descendente do RADARSAT-1 e Thematic Mapper do LANDSAT-5 em aplicação geológica na Amazônia. In: SIMP. BRAS. SENS. REM, 10, 2001. FoZ do Iguaçu. Anais... Fox do Iguaçu: INPE/SELPER, 2001. CD ROM.

PARADELLA, W.R., SANTOS, A. R., VENEZIANI, P., SANT'ANNA, M.V., MORAIS, M. C. de. Geological investigation using RADARSAT-1 images in the tropical rain forest environment of Brazil. Canadian Journal of Remote Sensing, v.26, n.2, p. 82-90, 2000.

PCI. Geomatica Software Solutions, reference manuals, version 9.0, PCI Geomatics Inc. Canada, 2003.

RESENDE, N.P., BARBOSA, A.L.de M. Relatório de pesquisa de minério de ferro, Distrito Ferrífero da Serra dos Carajás, Estado do Pará. Belém: AMZA, 1972. v. 1. 248p.

RIPLEY, E.A., REDMANN, R.E., CROWDER, A.A. Environmental effects of mining. Florida: St. Lucie Press, 1996. 396p.

SANTOS, P.R.A., GABOARDI, C., OLIVEIRA, L.C. Avaliação da precisão vertical dos modelos SRTM para a Amazônia. In: SIMP. BRAS. SENS. REM., 12, 2005. Goiânia. Anais... Goiânica: INPE/SELPER, 2005. v. 1, p. 4473-4480. (CDROM).

SILVA, M.F.F. da. Análise florística da vegetação que cresce sobre canga hematítica em Carajás-Pa (Brasil). Pará: Museu Paraense Emílio Goeldi, 1992.p. 79-108 (Série Especial do Boletim 7, v.2).

TOLBERT, G. E., TREIMANE, J.W., MELCHER, G.C., GOMES, C.B. The recently discovered Serra dos Carajás iron deposits, Northern Brazil. Economic Geology, v. 66, n. 7, p. 985-994, 1971.

Artigo recebido em 03/01/2008 e aprovado em 21/01/2009.

$$
\begin{gathered}
\text { A REM tem novo endereço: } \\
\text { FUNDAÇÃO GORCEIX - REM } \\
\text { Rua Carlos Walter Marinho Campos, } 57 \\
\text { Bairro: Vila Itacolomy } \\
\text { 35400-000 - Ouro Preto - MG }
\end{gathered}
$$

